\title{
Evaluation of Boswellia serrata enriched diet on cytokine gene expression and reactive oxygen metabolites in weaning piglets
}

\author{
G. Pastorelli', V. Serra ${ }^{1,3}$, G. Salvatori' ${ }^{2}$, V. Redaelli ${ }^{1}$ and L. Turin ${ }^{1}$ \\ ${ }^{1}$ University of Milan, Department of Veterinary Medicine, Via dell'Università 6, 26900, Lodi, Italy \\ ${ }^{2}$ University of Molise, Department of Medicine and Sciences for Health "V. Tiberio", \\ Via Francesco De Sanctis 1, 86100, Campobasso, Italy
}

KEY WORDS: animal welfare, botanical additives, cytokines, NF-kB, pigs, postweaning interval

Received: 20 November 2020

Revised: $\quad 22$ March 2021

Accepted: $\quad 8$ April 2021

${ }^{3}$ Corresponding author:

e-mail: valentina.serra@unimi.it

\begin{abstract}
Weaning is a stressful period that impacts piglet health leading to decreased performance and sometimes mortality. In recent years, public and scientific interest in dietary plant extracts tremendously increased because of their biological benefits. We hypothesized that the extract of the Indian frankincense Boswellia serrata, especially known for its anti-inflammatory properties, could affect piglets in the postweaning period when inflammation plays a crucial role. Eighty weaned piglets (40 gilts and 40 barrows, initial average body weight $10.0 \pm 0.43 \mathrm{~kg}$ ) were randomly assigned to one of two dietary treatments: control (CON) or CON diet supplemented with $1 \mathrm{~kg} / \mathrm{t}$ of $B$. serrata (BOSW). The trial lasted 28 days. Blood samples were collected at the beginning and the end of the trial. Skin lesions and thermal imaging were evaluated weekly. Growth performance, wellbeing parameters and gene expression levels of cytokines were not affected $(P>0.05)$, except for a trend in lower gene expression of interleukin(IL)-10 in BOSW group $(P=0.07)$. Time effect $(P<0.01)$ was observed for gene expression of IL-4, IL-6, IL-8 and tumour necrosis factor (TNF)-a, and sex effect $(P<0.05)$ was noted for gene expression of IL-1 $\beta$, IL- 6 and TNF-a, showing higher values for male than female piglets. Time changes in reactive oxygen metabolites (ROMs) blood concentration ( $\triangle \mathrm{ROMs}$ ) tended to be slower in BOSW group than in CON group $(P=0.056)$. These preliminary results indicate the need to investigate further doses and length of supplementation of $B$. serrata to verify the potential effects reported in other livestock species.
\end{abstract}

\section{Introduction}

Weaning is a stressful and complex period characterized by changes in diet, social, and environmental living conditions, which suddenly impact piglet health and lead to decreased performance and even mortality. The abrupt switch from highly digestible liquid milk to less-digestible solid feed has critical consequences on feed intake, resulting in a fasting period of $24-48 \mathrm{~h}$ and thus in a transiently reduced growth rate (Lallès et al., 2007). Several gastrointestinal changes are associated with the weaning transition, such as inflammation and atrophy in the small intestine, reduced villous height and recurrent diarrhoea. Furthermore, it was indicated that increased production of reactive oxygen species (ROS) is involved in the above mentioned weaning-induced gut dysfunctions, resulting in intestinal oxidative stress (Zhu et al., 2012). After the ban of antibiotics at subtherapeutic doses in livestock feeds in Europe in 2006, the search for alternative compounds with anti-inflammatory, antioxidant and immunomodulatory properties has been stimulated. In particular, interest in the use of plant-derived 
products as feed additives has increased significantly. These natural components are of potential interest due to their promising biological functions, such as antiviral, antibacterial, anti-inflammatory and antioxidant (Liu et al., 2018). Since ancient times, the extracts from the oleo-gum resin of Boswellia serrata Roxb. (family Burseraceae), also identified as Indian frankincense, have been used in traditional Ayurvedic medicine for the treatment of inflammatory diseases, such as colitis (Hartmann et al., 2014). This is a tree found mainly in India, but it is also present in the northeastern coast of Africa and in the Middle East. Extract from the bark contains chemical constituents including alkaloids, terpenoids, tannins, phenols, saponins and pentacyclic triterpenes (Hartmann et al., 2014). In the last decades, $B$. serrata extracts and preparations from gum resins of the plant have attracted increasing popularity in Western countries (Abdel-Tawab et al., 2011). Boswellia serrata is a botanical feed additive approved for the use in feed by the European Union Register of Feed Additives pursuant to Regulation (EC) No 1831/2003. In several in vitro (Mothana et al., 2011) and in vivo (Pungle et al., 2003) studies, it was shown that boswellic acids (BAs), which are the most bioactive molecules of B. serrata resin, have anti-inflammatory, anti-cancerous, antioxidative and immunomodulatory activities. The most active and promising anti-inflammatory agents are 3-O-acetyl-11-keto- $\beta$-boswellic acid (AKBA) and 11 -keto- $\beta$-boswellic acid (KBA), known to inhibit the 5-lipoxygenase enzyme that is involved in the inflammatory process. The gum resins from different Boswellia species vary in their BA composition (Abdel-Tawab et al., 2011); the gum resin of B. serrata contains quite similar amounts of $\mathrm{KBA}(3-4.7 \%)$ and AKBA (2.2-2.9\%), while the gum resin of African frankincense (B. carterii Birdw.) contains less $\operatorname{KBA}(0.5 \%)$ than $\mathrm{AKBA}(3.3 \%)$.

Although it has been demonstrated that B. serrata is beneficial as a natural feed additive in poultry and rabbits (Al-Yasiry et al., 2017; Ismail et al., 2019) to the best of our knowledge no studies with this plant have been performed in pig farming except a preliminary one (Pastorelli et al., 2017). We hypothesised that the biological activities of B. serrata described in the literature could affect also piglets in the postweaning period when inflammation plays a crucial role. Therefore, considering the limited available studies related to its application in pig farming, the aim of this pilot study was to evaluate the impact of dietary $B$. serrata extract on the gene expression of cytokines linked to inflammation in blood leukocytes and on the quantification of reactive oxygen metabolites in blood.

\section{Material and methods}

\section{Animals and treatments}

All procedures were carried out following the principles and ethical guidelines for the use of animals for scientific purposes and approved by the Ethics Committee of Animal Welfare of the University of Milan (OPBA_10_2018) according to the EU Directive 2010/63/EU.

In total, 80 four-week-old weaned piglets (LW-L $\times$ Talent Topics), 40 castrated males and 40 females, weighing $10.0 \pm 0.43 \mathrm{~kg}$, were randomly chosen from litters of contemporary sows and assigned to two dietary groups according to body weight (BW): basal diet (CON) composed of cereals (wheat, maize, barley), soyabean, fish meal, dried whey, skim milk, animal and vegetable fats, wheat by-products containing $17.5 \%$ crude protein $(\mathrm{CP}), 5.5 \%$ ether extract (EE), $3.5 \%$ crude fibre (CF), $4.5 \%$ ashes; and experimental diet (BOSW), consisting of basal diet with added $1 \mathrm{~kg} / \mathrm{t}$ of powder extract from gumresin of B. serrata. Premix contained the following per $\mathrm{kg}$ of the diet: $15000 \mathrm{IU}$ vitamin $\mathrm{A}$, $10 \mathrm{mg}$ vitamin $\mathrm{B}_{1}, 16 \mathrm{mg}$ vitamin $\mathrm{B}_{2}$ (riboflavin), 2000 IU vitamin D (cholecalciferol), $250 \mathrm{mg}$ vitamin E, $0.05 \mathrm{mg}$ vitamin $\mathrm{B}_{12}$ (cobalamin), $2 \mathrm{mg}$ vitamin $\mathrm{K}, 50 \mathrm{mg}$ vitamin $\mathrm{B}_{5}$ (niacin), $0.2 \mathrm{mg}$ biotin, $3 \mathrm{mg}$ folic acid, $375 \mathrm{mg}$ ferrous sulfate monohydrate, $77.6 \mathrm{mg} \mathrm{Mn}, 131 \mathrm{mg} \mathrm{Cu}$ oxide, $80.3 \mathrm{mg} \mathrm{Zn}$ oxide, $1.5 \mathrm{mg} \mathrm{I}$ and $0.3 \mathrm{mg}$ Se. The animals were fed $\mathrm{ad}$ libitum with free access to water; they were individually identified and distributed in 8 pens $(1.5 \mathrm{~m}$ wide $\times 1.5 \mathrm{~m}$ long) containing 10 piglets $/$ pen at controlled temperature $\left(26^{\circ} \mathrm{C}\right)$ and relative humidity (60\%). All piglets were vaccinated for Mycoplasma hyopneumoniae at day 7 of life. Body weight of piglets and pen feed consumption were measured (at day 0 and day 28) to calculate the average daily gain (ADG) and feed conversion ratio (FCR). The extract of B. serrata, provided by PR Bonfanti (Salsomaggiore Terme, Italy), consists of a powder soluble in alcohol and chloroform extracted from the gum-resin of the plant using a standardized procedure with ethyl acetate. The powder extract was standardized to contain $65 \%$ BA. The analyses on raw material, complying with the current edition of European Pharmacopoeia, reported a bacterial load of 
less than $1000 \mathrm{CFU} / \mathrm{g}$ and residual solvents of less than $5000 \mathrm{ppm}$.

\section{Blood samples collection and buffy coat preparation}

On day 0 and on day 28 blood samples were collected from the cranial vena cava of three randomly chosen piglets per pen $(3$ males/pen from two pens and 3 females/pen from the other two pens; the total number of samples: 24; 6 male and 6 female samples for each group). Collections were performed before the morning feeding; piglets were mildly restrained in dorsal recumbency by a trained operator, and blood was then collected via jugular venipuncture using a 20-gauge needle into EDTA and serum vacutainer tubes. Each EDTA tube was inverted 3-4 times to ensure adequate mixing of sample and anticoagulant. Blood specimens were immediately transferred to the laboratory for centrifugation at 3,500 $\mathrm{g}$ for $15 \mathrm{~min}$ at $4{ }^{\circ} \mathrm{C}$ to separate plasma and serum, which were stored at $-20^{\circ} \mathrm{C}$ until analyses.

Another blood sample was collected into EDTA tubes and concentrated leukocytes, indicated as a buffy coat, were separated according to the method described previously (Pastorelli et al., 2020). Shortly, $4 \mathrm{ml}$ of blood was added to $6 \mathrm{ml}$ of red blood cell lysis buffer $\left(1.4 \mathrm{M} \mathrm{NH}_{4} \mathrm{Cl}, 0.1 \mathrm{M} \mathrm{KHCO}, 3.5 \mathrm{mM}\right.$ EDTA, $\mathrm{pH} 8$ ) and vigorously mixed for $15 \mathrm{~min}$. The tubes were centrifugated at $300 \mathrm{~g}$ for $5 \mathrm{~min}$ at $4{ }^{\circ} \mathrm{C}$; the supernatant was eliminated, and the white blood cells were resuspended in $4 \mathrm{ml}$ of ice-cold red blood cell lysis buffer again. The tubes were vortexed and centrifugated at $300 \mathrm{~g}$ for $5 \mathrm{~min}$ at $4{ }^{\circ} \mathrm{C}$. The supernatant was eliminated and $4 \mathrm{ml}$ of room temperature phosphate-buffered saline (PBS, containing $137 \mathrm{mM}$ $\mathrm{NaCl}, 2.7 \mathrm{mM} \mathrm{KCl}, 10 \mathrm{mM} \mathrm{Na}{ }_{2} \mathrm{HPO}_{4} \cdot 2 \mathrm{H}_{2} \mathrm{O}, 2 \mathrm{mM}$ $\mathrm{KH}_{2} \mathrm{PO}_{4}, \mathrm{pH}$ 7.4) was added. The samples were further vortexed and centrifugated at $300 \mathrm{~g}$ for $5 \mathrm{~min}$ at $4{ }^{\circ} \mathrm{C}$. The supernatant was eliminated, and the pellet was resuspended in $1 \mathrm{ml}$ of a TRI ${ }^{\circledR}$ Reagent (SigmaAldrich, St. Louis, MO, USA) for RNA purification.

\section{RNA extraction, reverse transcription and Real-time PCR assays}

Total RNA was purified from blood specimens using the Trizol method. Samples were homogenized in $1 \mathrm{ml}$ of the TRI ${ }^{\circledR}$ Reagent by pipetting and then handled for RNA extraction according to the manufacturer's protocol. The RNA pellet was resuspended in a nuclease-free water and stocked at $-80{ }^{\circ} \mathrm{C}$ till use. Total RNA of each specimen was measured spectrophotometrically at $260 \mathrm{~nm}$ wavelength (BioPhotometer, Eppendorf, Hamburg, Germany). About $1 \mu \mathrm{g}$ of total RNA from each specimen was reverse transcribed to cDNA in a total volume of $25 \mu \mathrm{l}$ utilizing the High Capacity cDNA Archive kit with random hexamers according to the manufacturer's instructions (Applied Biosystem, Foster City, CA, USA) (Riva et al., 2010). The cDNA obtained was assayed in optimized Real-time PCR tests utilizing the 7000 Sequence Detection System (Applied Biosystem, Foster City, CA, USA) (Turin et al., 2007) to determine the expression of genes encoded selected cytokines (interleukin (IL)-1 $\beta$, IL-4, IL-6, IL-8, IL-10, tumour necrosis factor (TNF)- $\alpha$ and interferon (INF)- $\gamma$ ) and nuclear factor kappa-light-chain-enhancer of activated $B$ cells $(\mathrm{NF}-\kappa \mathrm{B})$. Swine specific primers were designed based on the porcine genome sequences accessible in the NCBI database (NM 214055.1 for IL-1 $\beta$, NM 214123.1 for IL-4, NM 214399.1 for IL-6, NM 213867.1 for IL-8, NM $21 \overline{4} 041.1$ for IL-10, NM_214022.1 for TNF- $\alpha$, NM_213948.1 for IFN- $\gamma$, NM_001048232.1 for NF-kB). The expression level of the endogenous control swine housekeeping gene $\beta$-actin (XM_021086047.1) was established for each sample to correct variations of purified mRNA quantity. All primers have been already presented by Pastorelli et al. (2020) and were designed with the use of a Primer Express software (Applied Biosystem, Foster City, CA, USA) across exons to prevent genomic DNA contamination, and were produced by Invitrogen (Carlsbad, CA, USA). Software BLAST available on PubMed web site was utilized for gene sequences retrieve and alignments. All reactions were carried out in duplicate at the following thermal cycle conditions: $10 \mathrm{~min}$ at $95^{\circ} \mathrm{C}$ followed by 40 cycles of $15 \mathrm{~s}$ at $95^{\circ} \mathrm{C}$ and $1 \mathrm{~min}$ at $60{ }^{\circ} \mathrm{C}$. Quantification was obtained by an algorithm applied to the data analyzed by the software of the 7000 Detection System (Applied Biosystems, Foster City, CA, USA). Gene expression was normalized by using the calculated $\beta$-actin cDNA expression (mean) of the same specimen and run. Data are given in arbitrary units (AU).

\section{Determination of reactive oxygen metabolites}

The serum concentration of reactive oxygen metabolites (ROMs) was measured by the d-ROMs test (Diacron International, Grosseto, Italy) according to the manufacturer's instructions. The test determines the concentration of hydroperoxides $(\mathrm{ROOH})$ generated in the cells by the attack of reactive oxygen species (ROS) on lipids, carbohydrates, amino acids, proteins and nucleotides. The colourimetric assay was based on the chromogen, $\mathrm{N}, \mathrm{N}$-diethylparaphenilendiamine, a substrate for 
alkoxyl and hydroperoxyl radicals, and the result was measured with a spectrophotometer (Jasco, V-530 iRM, Jasco International Co., Tokyo, Japan) at $576 \mathrm{~nm}$ absorbance. Samples were quantified using a standard and expressed as Carratelli units (Carr. U), where 1 Carr. U corresponds to $0.08 \mathrm{mg} / 100 \mathrm{ml} \mathrm{H}_{2} \mathrm{O}_{2}$. The concentration of the coloured complex was proportional to the level of hydroperoxides initially present in the sample.

\section{Wellbeing parameters}

Skin lesions. Skin lesions were evaluated the day before starting the feeding trial (baseline level day -1 ), and subsequently on days $7,14,21$ and 28 by a one trained observer. Pigs were observed standing, to ensure a complete view of the body. The five regions defined in the Welfare Quality ${ }^{\circledR}(2009)$ were evaluated in one side of each pig (ears, front, middle, hind-quarters and legs), giving a score of 'a' (up to 4 lesions), 'b' (5-10 lesions) or 'c' (11-15 lesions).

Thermal imaging. The skin temperatures were recorded on the dorsal, ocular and ear regions using an Avio thermoGear Nec G120EX microbolometer infrared camera (Nippon Avionics Co., Tokyo, Japan) $(320 \times 240$ pixels $)$. Data were acquired on the day before the feeding trial $(-1)$, on day 14 and day 28 of the trial by an operator standing at the entryway of every pen at about $3 \mathrm{~m}$ from the animals and at a height of $1.60 \mathrm{~m}$. The camera was automatically calibrated prior to any image and emissivity was set at 0.96 . Thermal images were downloaded and analyzed using NEC InfRec Analyzer and Grayess IRT Analyzer software (Nippon Avionics Co., Ltd., Tokyo, Japan).

\section{Statistical analyses}

Statistical analyses were performed using SPSS 24 for Windows (SPSS, Inc., Chicago, IL, USA). Prior to hypothesis testing, data were examined for normality. Distribution was normal except for gene expression of IL-4 and IL-6, TNF- $\alpha$ and IFN- $\gamma$ which were analysed with a non-parametric test. Performance data were analysed using the ANOVA procedure with dietary treatment and sex as main effects. Thermal imaging and blood parameters were analysed by two-way ANOVA, considering dietary treatment and time as fixed factors. Differences between periods were assessed by the Tukey post-hoc test for multiple comparisons. For the growth data and thermal imaging, a pen was considered as the experimental unit. Individual data were taken to be the experimental unit for blood parameters and skin lesions. The likelihood ratio and chi-square tests were used to compare skin lesion type categories with dietary treatment. Dietary treatment, sample day, sex and their interactions were considered as fixed effects for cytokine expression analyses. Treatment effects were deemed significant at $P<0.05$ and a trend was noted when $P<0.1$.

\section{Results}

\section{Growth performance}

Overall, no significant differences between CON and BOSW groups were found (Table 1). The final BW did not differ between experimental groups. The ADG for BOSW group showed just a trend $(P=$ $0.067)$ for a higher value in comparison to $\mathrm{CON}$ group. No significant difference in FCR was found between the two groups. No significant difference between males and females was observed as well (data not shown). Neither mortality nor morbidity was registered throughout the entire trial period.

Table 1. Effect of dietary Boswellia serrata extract on growth performance of postweaning piglets

\begin{tabular}{lccll}
\hline Indices & Groups $^{1}$ & & \multirow{2}{*}{ SEM } & P-value \\
\cline { 2 - 3 } & CON & BOSW & & \\
\hline Initial BW, kg & 10.12 & 9.71 & 0.176 & ns \\
Final BW, kg & 24.66 & 25.84 & 0.410 & ns \\
ADG, g/d & 519 & 576 & 0.016 & 0.065 \\
FCR, kg/kg & 1.41 & 1.44 & 0.046 & ns \\
\hline
\end{tabular}

${ }^{1}$ groups: CON - piglets fed basal diet, BOSW - piglets fed basal diet supplemented with $B$. serrata extract standardized for boswellic acids; BW - body weight; ADG - average daily gain; $F C R$ - feed conversion ratio; ns - not significant $(P>0.05)$ and lack of trend $(P>0.01)$; SEM - standard error of the mean

\section{Gene expression analysis and d-ROMs test}

The expression level of genes encoding proinflammatory (IL-1 $\beta$, IL-6, IL- 8, TNF- $\alpha$ and INF- $\gamma$ ) and anti-inflammatory (IL-4, IL-10) cytokines as well as NF- $\mathrm{KB}$ in white blood cells was analyzed through a Real-time RT-PCR assay. The effect of dietary $B$. serrata extract on the mRNA level of genes encoding multiple cytokines and NF- $\mathrm{kB}$ is summarized in Table 2 along with ROMs serum concentration. In this study, the gene expression level of all analyzed cytokines did not show a statistically significant difference between CON and BOSW groups, except for gene expression of IL-10 which showed just a trend $(P=0.07)$. A significant time effect was detected for gene expression of IL-4, IL-6, IL-8 and TNF- $\alpha(P<0.05)$, showing higher values at day 28 in comparison to day 0 . Conversely, mRNA levels of IL-10, IFN- $\gamma$ and NF- $\mathrm{kB}$ did not show any significant value both considering time and sex effect. Concerning the sex effect, statistically significant values were 
Table 2. Effect of dietary Boswellia serrata extract on the gene expression level of cytokines in white blood cells (mean \pm SE, expressed as arbitrary units) and on blood concentration of reactive oxygen metabolites (mean $\pm \mathrm{SE}$, expressed as Carr. $\mathrm{U}$ ) in postweaning piglets ${ }^{1}$

\begin{tabular}{|c|c|c|c|c|c|c|}
\hline \multirow{2}{*}{ Indices } & \multicolumn{2}{|l|}{ Day 0} & \multicolumn{2}{|l|}{ Day 28} & \multicolumn{2}{|c|}{$P$-value } \\
\hline & $\overline{\mathrm{CON}}$ & BOSW & $\mathrm{CON}$ & BOSW & time & diet \\
\hline \multicolumn{7}{|l|}{ Gene expression, $A U$} \\
\hline IL-1 $\beta$ & $9.56 \pm 0.80$ & $9.24 \pm 0.49$ & $8.61 \pm 0.74$ & $10.71 \pm 1.18$ & ns & ns \\
\hline IL-4 & $3.11 \pm 1.62$ & $5.28 \pm 2.27$ & $8.52 \pm 2.17$ & $11.63 \pm 2.10$ & ns & ns \\
\hline IL-6 & $10.66 \pm 1.11$ & $10.99 \pm 1.18$ & $13.87 \pm 0.51$ & $13.22 \pm 0.69$ & 0.006 & ns \\
\hline IL-8 & $7.44 \pm 0.68$ & $4.77 \pm 0.71$ & $9.42 \pm 0.67$ & $9.58 \pm 1.59$ & 0.002 & ns \\
\hline IL-10 & $9.45 \pm 0.49$ & $7.72 \pm 0.43$ & $9.08 \pm 0.61$ & $7.40 \pm 1.66$ & ns & 0.07 \\
\hline TNF-a & $9.26 \pm 0.98$ & $8.34 \pm 0.88$ & $10.19 \pm 0.65$ & $12.87 \pm 0.59$ & 0.001 & ns \\
\hline NF-kB & $6.23 \pm 1.62$ & $9.64 \pm 1.75$ & $11.22 \pm 1.20$ & $7.01 \pm 2.16$ & ns & ns \\
\hline INF-y & $6.12 \pm 0.39$ & $5.28 \pm 0.60$ & $5.71 \pm 0.55$ & $5.25 \pm 1.23$ & ns & ns \\
\hline $\begin{array}{l}\text { ROMs blood } \\
\text { concentration, Carr. U }\end{array}$ & $477.28 \pm 34.13$ & $513.30 \pm 33.02$ & $690.93 \pm 21.19$ & $641.39 \pm 30.28$ & 0.001 & ns \\
\hline
\end{tabular}

${ }^{1}$ groups: CON - piglets fed basal diet, BOSW - piglets fed basal diet supplemented with $B$. serrata extract standardized for boswellic acids; ROMs - reactive oxygen metabolites; IL - interleukin; TNF- $\alpha$ - tumour necrosis factor $\alpha$; NF-kB - nuclear factor kappa-light-chain-enhancer of activated B cells; INF- $\gamma$ - interferon $\gamma$; ns - not significant $(P>0.05)$ and lack of trend $(P>0.01)$; SE - standard error

Table 3. Descriptive statistics of temperatures (mean $\pm \mathrm{SE}$ ) measured on the surface of the dorsal, ocular and ear regions of piglets fed diets with or without Boswellia serrata extract addition

\begin{tabular}{|c|c|c|c|c|c|}
\hline \multirow{2}{*}{$\begin{array}{l}\text { Temperature, } \\
{ }^{\circ} \mathrm{C}\end{array}$} & \multicolumn{2}{|l|}{ Group ${ }^{1}$} & \multirow{2}{*}{ Average } & \multicolumn{2}{|c|}{$P$-value } \\
\hline & $\mathrm{CON}$ & BOSW & & time & diet \\
\hline \multicolumn{6}{|l|}{ Eye } \\
\hline day -1 & $38.37 \pm 0.07$ & $38.19 \pm 0.12$ & $38.28^{A}$ & & \\
\hline day 14 & $38.50 \pm 0.10$ & $38.47 \pm 0.09$ & $38.49^{B}$ & & \\
\hline day 28 & $38.02 \pm 0.12$ & $38.27 \pm 0.07$ & $38.14^{\mathrm{A}}$ & 0.002 & ns \\
\hline \multicolumn{6}{|l|}{ Ear } \\
\hline day -1 & $38.9 \pm 0.08$ & $39.06 \pm 0.09$ & $39.00^{\mathrm{A}}$ & & \\
\hline day 14 & $39.1 \pm 0.13$ & $38.86 \pm 0.09$ & $38.99^{A}$ & & \\
\hline day 28 & $38.4 \pm 0.07$ & $38.97 \pm 0.06$ & $38.69^{B}$ & 0.001 & 0.056 \\
\hline \multicolumn{6}{|l|}{ Back } \\
\hline day -1 & $38.2 \pm 0.08$ & $38.07 \pm 0.08$ & $38.12^{\mathrm{A}}$ & & \\
\hline day 14 & $38.3 \pm 0.09$ & $38.15 \pm 0.12$ & $38.23^{A}$ & & \\
\hline day 28 & $37.8 \pm 0.09$ & $38.01 \pm 0.09$ & $37.89^{B}$ & 0.001 & ns \\
\hline
\end{tabular}

${ }^{1}$ groups: CON - piglets fed basal diet, BOSW - piglets fed basal diet supplemented with $B$. serrata extract standardized for boswellic acids; ns - not significant $(P>0.05)$ and lack of trend $(P>0.01) ; \mathrm{SE}$ - standard error; ${ }^{A B}$ - values with different superscripts for each parameter within each column are significantly different at the indicated $P$-value

detected for IL-1 $\beta(P=0.045)$, IL-6 $(P=0.043)$ and TNF- $\alpha(P=0.002)$, while a trend was shown for IL-8 $(P=0.08)$. In detail, sex impacted the gene expression level of these cytokines showing in male pigs values higher than in females (Figure 1).

The average value of ROMs concentration was within the range of 477-691 Carr. U (Table 2). No effect of diet was found between examined groups in the case of ROMs concentration; however, time changes in ROMs blood concentration $(\triangle \mathrm{ROMs})$ tended to be slower in BOSW group $(P=0.056)$ than in CON group (Figure 2).

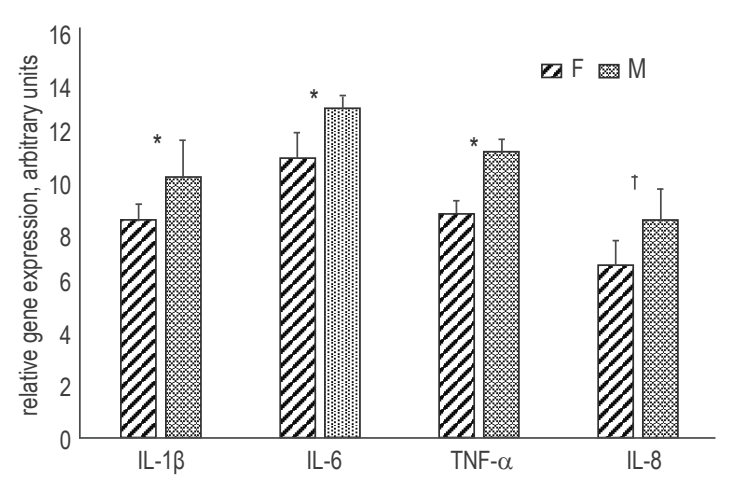

Figure 1. Sex impact on the gene expression level of a selected panel of cytokines (mean $\pm \mathrm{SE}$ )

* - indicates a significant difference between males and females $(P<0.05) ; \dagger-$ indicates a difference which tends to be significant between males and females $(P=0.08) ; F-$ females; $M$ - males; SE - standard error; IL - interleukin; TNF- - tumour necrosis factor a

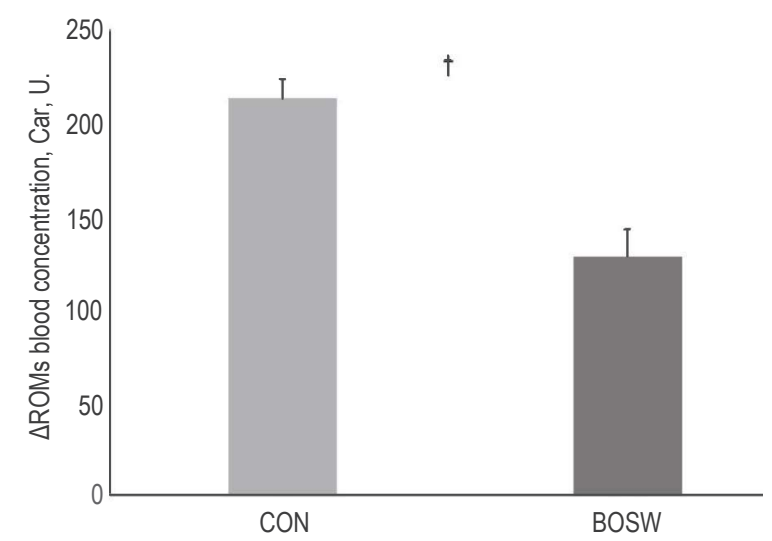

Figure 2. Time changes $(\Delta)$ in blood concentration of reactive oxygen metabolites (ROMs) (mean \pm SE; expressed in Carr. U) between day 28 and day 0 in CON and BOSW groups (CON - piglets receiving a basal diet; BOSW - piglets receiving a basal diet supplement with Boswellia serrata extract standardized for boswellic acids); $\dagger-$ indicates a difference which tends to be significant $(P=0.056)$ 


\section{Wellbeing parameters}

Each pig was scored using a 0 -to-2 scale, where 0 corresponded to a pig having the full-body till up to 4 lesions, 1 to a pig having any body region with $5-10$ lesions and/or a maximum of one region with 11-15 lesions; 2 to a pig having at least two body regions with 11-15 lesions or at least one body region with more than 15 lesions. The average percentage of skin lesion equal 1 on a total of observations was $0,12.5,22.5,25$ and $30 \%$ at a basal level at days 7, 14, 21 and 28, respectively. Skin lesions did not show any significant difference between CON and BOSW groups at each time point.

The descriptive statistics for surface temperature measured for eye, ear and back regions are reported in Table 3. In the present study, no significant effect of dietary treatment was detected for surface temperature in any of the regions analyzed, except for the ear region, in which BOSW group showed values tendentially higher than in CON group.

\section{Discussion}

The investigation of the effects of dietary $B$. serrata on inflammation cytokines in white blood cells and ROMs blood concentration of postweaning piglets was the focus of this pilot study. To the best of our knowledge, the only studies available in the literature concerning the effect of $B$. serrata on the growth performance of livestock species are those performed on poultry and rabbits, in which a significant improvement in FCR and/or body weight gain was demonstrated for both species (Al-Yasiry et al., 2017; Ismail et al., 2019). In all mentioned studies, $B$. serrata was used at higher doses than in the present study. However, broiler chickens fed increasing dietary B. serrata supplementation (3-4-5\%) demonstrated that doses exceeding $4 \%$ were detrimental to beneficial effects of this phytobiotic (Al-Yasiry et al., 2017). Moreover, in rabbits, an intermediate dosage $(0.25-0.5 \%)$ showed an improvement in FCR (Ismail et al., 2019). A similar occurrence was observed in rats (Singh et al., 2008). Therefore, aware that an excess of this supplement may be responsible for a beneficial failure, and knowing from the prior study in pigs that $0.05 \%$ supplement (Pastorelli et al., 2017) was not sufficient to elicit effects, we hypothesized that an increase (doubling that amount to $0.1 \%$ ) could be beneficial. Nevertheless, we are knowledgeable about much higher doses used in some species (e.g., chicken). It is also quite difficult to compare doses effective in light animals such as chickens and rabbits with those potentially effective in heavier animals such as piglets. At this point, it is clear that $0.1 \%$ supplement is still not sufficient to improve efficiency and productivity in piglets in the postweaning period. Further experiments with higher doses and/or extended administration time (e.g., up to 6 weeks) could provide necessary elucidations.

The early weaning process is commonly associated with intestinal barrier dysfunction and mucosal inflammation in weaned piglets, which are responsible for the stunted growth and diarrhoea observed in the first two weeks after weaning. Indeed, in previous studies, it was shown an intestinal upregulation of several mediators of inflammation such as IL-1 $\beta$, IL-6, IL-8 and TNF- $\alpha$, as well as blood upregulation of pro-inflammatory cytokines (Pié et al., 2004). In addition, previous research has shown that psychological stress, such as early social isolation, influences the pro-inflammatory cytokine response of pigs (Tuchscherer et al., 2004). Several studies performed both in vivo and in vitro support the potential of BAs, the main active substances of $B$. serrata, for the treatment of a variety of inflammatory disorders due to the ability to inhibit the synthesis of leukotrienes, the chemical mediators of inflammation in various inflammatory diseases. In particular, a study conducted in rats with collagen-induced arthritis has shown a positive effect of the oral administration of $B$. serrata extract on oxidative stress and inflammatory mediators, resulting in significantly reduced levels of IL-1 $\beta$, IL- 6 , TNF- $\alpha$ and IFN- $\gamma$, and increased levels of IL-10 (Umar et al., 2014). On the other hand, inflammatory mediators such as TNF- $\alpha$ and IL- $1 \beta$ are considered the main endogenous pyrogens, and they were observed to increase in piglets in response to stress-inducing stimuli and injury such as trauma caused by castration (Moya et al., 2008). In this study piglets were healthy and a response from the addition of natural feed additive is expected when animals are in a stressful environment. In agreement with the aforementioned studies, the expression level of the anti-inflammatory IL-10 obtained in this work showed a trend towards down-regulation, albeit not statistically significant. In fact, IL-10 is a potent anti-inflammatory cytokine produced mainly by $\mathrm{M}-2$ type macrophages, Th-2 lymphocytes, $\mathrm{T}$ and $\mathrm{B}$ regulatory lymphocytes with the aim to dampen the aberrant production of pro-inflammatory cytokines through different pathways. A more evident down-regulation of IL-10 expression in the blood of pigs that received $B$. serrata enriched diet may be explained with 
a reduced need for such anti-inflammatory signal as a result of a beneficial effect of the natural compound. The significant time effect detected for IL4, IL-6, IL-8 and TNF- $\alpha$, showing higher values of gene expression at day 28 compared to day 0 , is in agreement with what reported by other and the same authors in a different study with pigs of the same weight class and genetic type (Turin et al., 2019). Differences related to sex in the expression level of inflammatory markers have been demonstrated in several studies conducted both in vitro and in vivo in human and animal species. An in vitro study performed using whole blood after incubation with lipopolysaccharides demonstrated a higher concentration of TNF- $\alpha$ and IL- 6 in men than women (Lefèvre et al., 2012). This result suggests that men produce larger amounts of TNF- $\alpha$ because they have a higher number of circulating monocytes compared to women. Moreover, pieces of evidence suggest that estrogens inhibit the production of Th1 proinflammatory cytokines, such as TNF- $\alpha$, explaining the lower values seen in females, and this is in line with our results (Salem, 2004). A hormonal difference between male and female is appreciable since intrauterine life (Goxe et al., 1993).

The ROMs concentrations increased as the piglets grew (time effect), which is in accordance with to some studies in which an increase of oxidative products in plasma has been shown during the second month of life of piglets, and thus after weaning (Buchet et al., 2017). The ROMs parcitipate in reactions that, if uncontrolled, may impair the animal performance, and it was not observed in our study. It has been suggested that the high metabolic rate of growing tissues generates large amounts of free radicals (Skaperda et al., 2019). In pigs addressed for the selection of genotypes oriented to reduce fat and to increase growth, ROMs values are higher than in those characterized by low growth rate (Ballerini et al., 2003). The study conducted by Sierżant et al. (2019) investigated the oxidative production of pigs divergently selected for feed efficiency and the authors found values higher than those found in the present paper. In other words, ROMs can vary among genetic types; anyway, the lower increment found in pigs of the BOSW group is to be considered as a positive result. The average of ROMs values found herein agrees with the results reported by previous works performed on pigs (Pastorelli et al., 2012).

According to the literature, fighting to establish a social hierarchy occurs during the first days after mixing unfamiliar piglets at weaning, with increased stress level and oxidative stress (Fels et al., 2014). The increase in the percentage of skin lesions found herein can be related to the rank-order fighting between piglets, independently of dietary treatment; anyway, no severe lesion has been observed, also no effect on ROMs values between groups has been noted, because of satisfactory farm management.

Infrared thermography imaging represents a non-invasive technique for the early detection of inflammation also in the veterinary field (Jacob et al., 2016). The use of infrared thermography in experimental pig farms has been recently widely used, such as environmental enrichment at weaning, castration of piglets and stress in postweaning piglets (Pulido-Rodriguéz, 2017; Pérez-Pedraza et al., 2018; Yáñez-Pizaña et al., 2019). Conversely, studies covering the use of infrared thermography to detect inflammatory conditions in animals have had very little focus on pigs. In pigs, a study conducted on osteoarthrosis tarsi deformans found significant disease-related temperature differences in the superficial temperature of the tarsus (Sabec and Lazar, 1990) while another study used thermography to detect lameness in sows (Amezcua et al., 2014). The most appealing aspect of this method is that it is a remote, noncontact and noninvasive process for acquiring individual animal data (Rekant et al., 2016). In pigs, the ear skin temperature is a good measure of thermoregulatory responses, since this region can minimize blood flow through vasoconstriction in response to cold or increase it by vasodilation in response to heat (Andersen et al., 2008). In general, body temperature was reported to increase in response to anxiogenic or stress-inducing stimuli and injury for the activation of the endogenous mechanisms related to inflammation (Olivier et al., 2003). In the present study, we attributed the numerically higher ear skin temperature observed on day 28 to the increased vasodilation caused by Boswellia extracts as previously shown in vitro (Oleski et al., 2006) since no inflammation or morbidity was registered in animals.

\section{Conclusions}

The dietary supplementation of Boswellia serrata did not affect the growth performance of postweaning piglets. The integrated diet was unable to alter pro- and anti-inflammatory cytokines gene expression in white blood cells except for a trend of down-regulation for IL-10 gene expression. However, a blood concentration of reactive oxygen metabolites (ROMs) tended to increase slower in B. serrata 
supplemented group. No effects of $B$. serrata addition were detected on wellbeing parameters.

We are aware that the composition of $B$. serrata extract and total antioxidant defences (enzymatic, non-enzymatic) together with ROS production will have to be taken into account to define the role of boswellic acids on organism function. Further studies using increasing doses of $B$. serrata extract in the diet of postweaning piglets and different lengths of supplementation will be needed to better understand the effect of this potentially promising botanical additive.

\section{Acknowledgments}

The authors thank the University of Milano, for financial support (Linea 2, 2017). The authors are also grateful to Dr. Pellacini Mario and Dr. Pizzi Barbara for their technical and practical support in the field and Roberta Torinesi for taking part in the laboratory assays.

\section{Conflict of interest}

The authors declare that there is no conflict of interest.

\section{References}

Abdel-Tawab M., Werz O., Schubert-Zsilavecz M., 2011. Boswellia serrata - an overall assessment of in vitro, preclinical, pharmacokinetic and clinical data. Clin. Pharmacokinet. 50, 349-369, https://doi.org/10.2165/11586800-000000000-00000

Al-Yasiry A.R.M., Kiczorowska B., Samolińska W., Kowalczuk-Vasilev E., Kowalczyk-Pecka D., 2017. The effect of Boswellia serrata resin diet supplementation on production, haematological, biochemical and immunological parameters in broiler chickens. Animal 11, 1890-1898, https://doi.org/10.1017/ S1751731117000817

Amezcua R., Walsh S., Luimes P.H., Friendship R.M., 2014. Infrared thermography to evaluate lameness in pregnant sows. Can. Vet. J. 55, 268-272

Andersen H.M.L., Jørgensen E., Dybkjær L., Jørgensen B., 2008. The ear skin temperature as an indicator of the thermal comfort of pigs. Appl. Anim. Behav. Sci. 113, 43-56, https://doi. org/10.1016/j.applanim.2007.11.003

Ballerini A., Civitareale C., Fiori M., Regini M., Betti M., Brambilla G., 2003. Traceability of inbred and crossbred Cinta Senese pigs by evaluating the oxidative stress. J. Vet. Med. 50, 113-116, https://doi.org/10.1046/j.1439-0442.2003.00508.x

Buchet A., Belloc C., Leblanc-Maridor M., Merlot E., 2017. Effects of age and weaning conditions on blood indicators of oxidative status in pigs. PLoS ONE 12, e0178487, https://doi. org/10.1371/journal.pone.0178487

Fels M., Hartung J., Hoy S., 2014. Social hierarchy formation in piglets mixed in different group compositions after weaning. Appl. Anim. Behav. Sci. 152, 17-22, https://doi.org/10.1016/j. applanim.2014.01.003
Goxe B., Prunier A., Remy J.J., Salesse R., 1993. Ontogeny of gonadal luteinizing hormone and follicle-stimulating hormone receptors in the fetal pig and related changes in gonadotropin and testosterone secretion. Biol. Reprod. 49, 609-616, https://doi. org/10.1095/biolreprod49.3.609

Hartmann R.M., Fillmann H.S., Martins M.I.M., Meurer L., Marroni N.P., 2014. Boswellia serrata has beneficial anti-inflammatory and antioxidant properties in a model of experimental colitis. Phytother. Res. 28, 1392-1398, https://doi.org/10.1002/ ptr.5142

Ismail I.E., Abdelnour S.A., Shehata S.A., Abd El-Hack M.E., El-Edel M.A., Taha A.E., Schiavitto M., Tufarelli V., 2019. Effect of dietary Boswellia serrata resin on growth performance, blood biochemistry, and cecal microbiota of growing rabbits. Front. Vet. Sci. 6, 471, https://doi.org/10.3389/fvets.2019.00471

Jacob F.G., dos S. Baracho M., de A. Nääs I., Souza R., D’Alessandro Salgado D., 2016. The use of infrared thermography in the identification of pododermatitis in broilers. Eng. Agrícola 36, 253-259, https://doi.org/10.1590/1809-4430-Eng.Agric. v36n2p253-259/2016

Lallès J.P., Bosi P., Smidt H., Stokes C.R., 2007. Nutritional management of gut health in pigs around weaning. Proc. Nutr. Soc. 66, 260-268, https://doi.org/10.1017/S0029665107005484

Lefèvre N., Corazza F., Duchateau J., Desir J., Casimir G., 2012. Sex differences in inflammatory cytokines and CD99 expression following in vitro lipopolysaccharide stimulation. Shock 38 , 37-42, https://doi.org/10.1097/SHK.0b013e3182571e46

Liu Y., Espinosa C.D., Abelilla J.J. et al., 2018. Non-antibiotic feed additives in diets for pigs: a review. Anim. Nutr. 4, 113-125, https://doi.org/10.1016/j.aninu.2018.01.007

Moya S.L., Boyle L.A., Lynch P.B., Arkins S., 2008. Effect of surgical castration on the behavioural and acute phase responses of 5-day-old piglets. Appl. Anim. Behav. Sci. 111, 133-145, https:// doi.org/10.1016/j.applanim.2007.05.019

Mothana R.A.A., Hasson S.S., Schultze W., Mowitz A., Lindequist U., 2011. Phytochemical composition and in vitro antimicrobial and antioxidant activities of essential oils of three endemic Soqotraen Boswellia species. Food Chem. 126, 1149-1154, https://doi.org/10.1016/j.foodchem.2010.11.150

Oleski A., Lindequist U., Mothana R.A.A., Melzig M.F., 2006. Screening of selected Arabian medicinal plant extracts for inhibitory activity against peptidases. Pharmazie 61, 359-361

Olivier B., Zethof T., Pattij T. et al., 2003. Stress-induced hyperthermia and anxiety: pharmacological validation. Eur. J. Pharmacol. 463, 117-132, https://doi.org/10.1016/S0014-2999(03)01326-8

Pastorelli G., Faustini M., Luzi F., Redaelli V., Turin L., 2020. Passiflora incarnata powder extract in postweaning piglets feeding slightly improves wellbeing and immune parameters. Livest. Sci. 235, 104000, https://doi.org/10.1016/j.livsci.2020.104000

Pastorelli G., Pellacini M., Pizzi B., 2017. Natural extracts in weaned piglets nutrition. In: I.C. De Jong, P. Koene (Editors). Proceedings of the $7^{\text {th }}$ International Conference on the Assessment of Animal Welfare at Farm and Group Level. Ede (The Netherlands). Wageningen Academic Publishers. Wageningen (The Netherlands), p. 246

Pastorelli G., Rossi R., Corino C., 2012. Influence of Lippia citriodora verbascoside on growth performance, antioxidant status, and serum immunoglobulins content in piglets. Czech J. Anim. Sci. 57, 312-322, https://doi.org/10.17221/6006-CJAS

Pérez-Pedraza E., Mota-Rojas D., González-Lozano M., GuerreroLegarreta I., Martínez-Burnes J., Mora-Medina P., CruzMonterrosa R., Ramírez-Necoechea R., 2018. Infrared thermography and metabolic changes in castrated piglets due to the effects of age and the number of incisions in the testicles. Am. J. Anim. Vet. Sci. 13, 104-114, https://doi.org/10.3844/ ajavsp.2018.104.114 
Pié S., Lallès J.P., Blazy F., Laffitte J., Sève B., Oswald I.P., 2004. Weaning is associated with an upregulation of expression of inflammatory cytokines in the intestine of piglets. J. Nutr. 134, 641-647, https://doi.org/10.1093/jn/134.3.641

Pulido-Rodriguéz L.F., Titto E.A.L., Henrique F.L., Longo A.L.S., Hooper H.B., Pereira T.L., Pereira A.M.F., Titto C.G., 2017. Infrared thermography of the ocular surface as stress indicator for piglets postweaning. Pesq. Vet. Bras. 37, 453-458, https://doi. org/10.1590/s0100-736x2017000500005

Pungle P., Banavalikar M., Suthar A., Biyani M., Mengi S., 2003. Immunomodulatory activity of boswellic acids of Boswellia serrata Roxb. Indian J. Exp. Biol. 41, 1460-1462

Rekant S.I., Lyons M.A., Pacheco J.M., Arzt J., Rodriguez L.L., 2016. Veterinary applications of infrared thermography. Am. J. Vet. Res. 77, 98-107, https://doi.org/10.2460/ajvr.77.1.98

Riva F., Rahman M.M., Turin L., Ceciliani F., Russo S., Tribbioli G., Lecchi C., 2010. TIR8 receptor expression in bovine tissues. Vet. Immunol. Immunopathol. 136, 65-70, https://doi.org/10.1016/j. vetimm.2010.02.009

Sabec D., Lazar P., 1990. Preliminary results of non-contact temperature measurements by an infrared thermometer to the ankle of the pig with osteoarthrosis tarsi deformans (in Deutch: Erste Ergebnisse berührungsloser Temperaturmessungen mittels eines Infrarotthermometers am Sprunggelenk des Schweines mit Osteoarthrosis tarsi deformans). Dtsch. Tieräztl Wschr. 97 , 43-44

Salem M.L., 2004. Estrogen, a double-edged sword: modulation of TH1and TH2-mediated inflammations by differential regulation of TH1/TH2 cytokine production. Curr. Drug Targets Inflamm. Allergy 3, 97-104, https://doi.org/10.2174/1568010043483944

Sierżant K., Perruchot M.H., Merlot E., Le Floc'h N., Gondret F., 2019. Tissue-specific responses of antioxidant pathways to poor hygiene conditions in growing pigs divergently selected for feed efficiency. BMC Vet. Res. 15, 341, https://doi.org/10.1186/ s12917-019-2107-2

Singh S., Khajuria A., Taneja S.C., Khajuria R.K., Singh J., Johri R.K., Qazi G.N., 2008. The gastric ulcer protective effect of boswellic acids, a leukotriene inhibitor from Boswellia serrata, in rats. Phytomedicine 15, 408-415, https://doi.org/10.1016/j. phymed.2008.02.017
Skaperda Z., Veskoukis A.S., Kouretas D., 2019. Farm animal welfare, productivity and meat quality: Interrelation with redox status regulation and antioxidant supplementation as a nutritional intervention (Review). World Acad. Sci. J. 1, 177-183, https:// doi.org/10.3892/wasj.2019.19

Tuchscherer M., Kanitz E., Puppe B., Tuchscherer A., Stabenow B., 2004. Effects of postnatal social isolation on hormonal and immune responses of pigs to an acute endotoxin challenge. Physiol. Behav. 82, 503-511, https://doi.org/10.1016/j. physbeh.2004.04.056

Turin L., Tribbioli G., Invernizzi P., Grati F.R., Crema S., Laible G., Riva F., 2007. Fetal microchimerism in normal and embryo transfer bovine pregnancies. Vet. Res. Commun. 31, 205-207, https:// doi.org/10.1007/s11259-007-0095-3

Turin L., Torinesi R., Pastorelli G., 2019. Real-time PCR detection of the effect of postweaning on the expression of cytokines and NK-KB in piglets. J. Biol. Regul. Homeost. Agents 33, 1737-1745, https://doi.org/10.23812/19-342-A

Umar S., Umar K., Sarwar A.H., Khan A., Ahmad N., Ahmad S., Katiyar C.K., Husain S.A., Khan H.A., 2014. Boswellia serrata extract attenuates inflammatory mediators and oxidative stress in collagen induced arthritis. Phytomedicine 21, 847-856, https://doi.org/10.1016/j.phymed.2014.02.001

Yáñez-Pizaña A., Mota-Rojas D., Ramírez-Necoechea R., CastilloRivera M., Roldán-Santiago P., Mora-Medina P., GonzálezLozano M., 2019. Application of infrared thermography to assess the effect of different types of environmental enrichment on the ocular, auricular pavilion and nose area temperatures of weaned piglets. Comput. Electron. Agric. 156, 33-42, https://doi.org/10.1016/j.compag.2018.11.010

Zhu L.H., Zhao K.L., Chen X.L., Xu J.X., 2012. Impact of weaning and an antioxidant blend on intestinal barrier function and antioxidant status in pigs. J. Anim. Sci. 90, 2581-2589, https://doi.org/10.2527/jas.2011-4444 